Article

\title{
Social Media-Related Geographic Information in the Context of Strategic Environmental Assessment of Municipal Masterplans: A Case Study Concerning Sardinia (Italy)
}

\author{
Roberta Floris and Corrado Zoppi * \\ Department of Civil and Environmental Engineering and Architecture, University of Cagliari, \\ Via Marengo 2, Cagliari 09123, Italy; E-Mail: roberta.floris@unica.it \\ * Author to whom correspondence should be addressed; E-Mail: zoppi@unica.it; \\ Tel.: +39-070-675-5216; Fax: +39-070-675-5215.
}

Academic Editor: Andrew Hudson-Smith

Received: 28 June 2015 / Accepted: 4 August 2015 / Published: 7 August 2015

\begin{abstract}
This paper proposes a discussion concerning the use of social media-related geographic information in the context of the strategic environmental assessment (SEA) of Sardinian Municipal masterplans (MMPs). We show that this kind of information improves, substantially, the SEA process since it provides planners, evaluators, and the local communities with information retrieved from social media that would have not been available otherwise. This information integrates authoritative data collection, which comes from official sources, and enlightens tastes and preferences of the users of services and infrastructure, and their expectations concerning their spatial organization. A methodological approach related to the collection of social media-related geographic information is implemented and discussed with reference to the urban context of the city of Cagliari (Sardinia, Italy). The results are very effective in terms of provision of information, which may possibly increase the spatial knowledge available for planning policy definition and implementation. In this perspective, this kind of information discloses opportunities for building analytical scenarios related to urban and regional planning and it offers useful suggestions for sustainable development based on tourism strategies.
\end{abstract}

Keywords: Strategic environmental assessment (SEA); municipal masterplans; geographic information; sustainable development 


\section{Introduction}

An important condition for strategic environmental assessment (SEA) to be effective, in the spirit of Directive 2001/42/EC (named as the "Directive", from now on) which rules over it, is represented by its inclusive attitude.

SEA is defined by Thérivel [1] as a formal, systematic, and holistic assessment process concerning the environmental impacts of a plan or a program, and of its alternatives, which entails the preparation of a written report, whose results have to be made available to the public and implemented into the policy-, plan-, or program-related decision-making process. In this conceptual framework, SEA not only must be considered a descriptive and sectoral analysis related to the impacts generated by planning policies on the environmental resources, but also a process that follows through and eventually identifies itself with the decision-making and implementation phases of plans and programs; that is with the definition and attainment of their strategies [2]. As a consequence, SEA is ontologically-connected to the assessment of how issues concerning sustainability and protection of environmental resources are integrated into the definition of the plans' and programs' objectives, from the starting phases of their elaboration, and into the implementation of their policies [3-5].

Under this perspective, SEA is intrinsically founded on the sustainability paradigm, and a SEA-oriented plan or program is a plan or program based on sustainability-related objectives. These objectives are integrated into the plan's or program's strategy, which should include social and economic development-related objectives as well [6].

The SEA of a MMP develops through the plan's decision-making process as a continuous assessment of the consistency of the social and economic-development-related objectives with the sustainability objectives, and builds a holistic strategic vision concerning the future of the spatial organization of the municipal area, which aims at increasing the awareness of public and private stakeholders on the importance of the sustainability-related issues in the comprehensive system of the objectives of the MMP [7,8].

The SEA process, which couples plan definition and establishment, and its implementation, is characterized by a set of phases which should be responsibly and carefully developed in the interest of the process key-actors, who should not reasonably give up, since, the process being transparent, at best, such a decision would most likely appear to the voters of their local communities as a symptom of incapacity and sloth [9].

It is evident that the SEA process is an ex ante and ongoing assessment. It is also clear that SEA aims at finding the best way to represent the focus of all interests and expectations at stake, and at defining and implementing planning decisions which most part of the key-actors would agree upon [10].

The process of enactment of the Legislative Decree n. 2006/152, which acknowledges the SEA-related Directive, in its evaluation is strongly focused on the inclusive and incremental definition of the objectives of the policies which need to be assessed, and on the effective participation of all the key-actors in the process, as regards both the preliminary and ongoing evaluations. A good practice is represented by the experience of the Sardinian municipal masterplans adjustment process to the regional landscape plan (RLP).

The method adopted for the implementation of the SEA process is very important since, being inclusive and incremental, it shows some of the main characteristics needed for assessment to be effective. In other words, SEA concerning the adjustment of the Sardinian MMPs to the RLP is a 
significant and exportable practice for the environmental assessment of complex planning processes. Therefore, it is important to discuss some issues concerning such an assessment approach. The innovation brought about by the Sardinian case, which is particularly significant in terms of exportability, consists of a methodological approach which is in an advanced experimental stage, since several municipalities and provinces are implementing SEA processes with endogenously-identified planning/assessment objectives, and with decisions on program/plan actions taken with the aim of addressing suitable ways of reaching such objectives.

The importance of Sardinian SEA can be found in the fact that the Region has defined guidelines (GL) [11] that not only formally guarantee the development of an incremental and inclusive process, but also mark the phases, so that the proceeding authorities, i.e., a municipality council or a province, tend to include all the potential actors, whether they are public, private or non-profit, associations or private citizens, so as to come to a rapid completion of the evaluation process, thus implying the approval of the plan and its enactment. As a consequence, it is not reasonable that key-actors opt out of the project because the entire evaluation process is publicly visible and such an approach could possibly be seen by the local counterparts as a lack of interest or will to act. It is apparent that the SEA unfolds as an evaluation process ex ante and in itinere; it is also clear that the ultimate goal of the SEA is to find the best way to represent all the interests and needs that are at stake and especially to find as many compromises as possible so that all the key-actors' wants are represented in the decision-making phases. It is, therefore, an evaluation process which is basically orientated at creating inclusive consensus building among local populations in respect to choices which are aimed at protecting environmental resources and sustainable development. However, in the Sardinian case, its chief characteristics should be inclusivity and incrementalism, which are important aspects of assessment researches applied to complex processes.

This conceptual approach entails a planning-assessment process based on a logical framework (LF) which relates the plan actions to sustainability objectives through the plan objectives. As Figure 1 shows, the objectives of a MMP should address the sustainability objectives by means of the operational provisions of the plan.

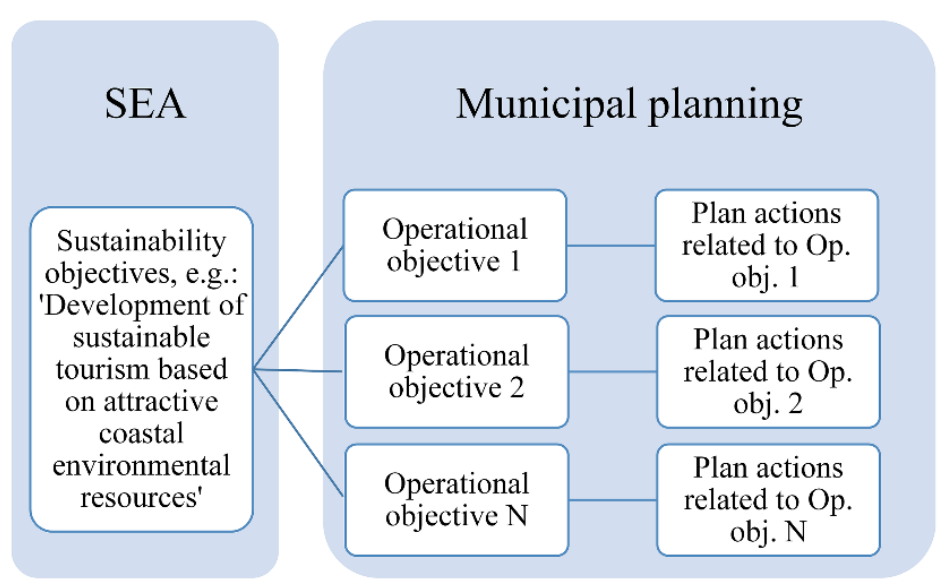

Figure 1. A scheme of the Sardinian MMPs related to the SEA process.

SEA implies the evaluation of the potentially-negative impacts of plan actions related to operational objectives on sustainability objectives and the consequential identification of measures, i.e., newly-defined 
plan actions, which either counter or mitigate such negative environmental impacts, which may eventually entail the elimination of particularly dangerous operations in terms of potential environmental damage.

The effectiveness of the process is based on the quality of the information available for the assessment. Social media-related geographic information is an important way for improving, substantially, the quality of information to make planning decisions that entail effective sustainability-oriented considerations.

Sustainability objectives are defined with reference to environmental components, which, in the case of the regional planning framework of Sardinia, are indicated by the guidelines issued by the Sardinian Region (GL) [11]. Sustainable coastal tourism is one of the main aspects related to the economic and productive system; that is, one of the eleven environmental components, the eighth of the list of the GL document. In the logical framework of the MMPs' SEA process shown in Figure 1, a sustainability objective concerning the masterplan of a Sardinian coastal municipality can be identified as "Development of sustainable tourism based on attractive coastal environmental resources".

Starting from this sustainability objective, the implementation of the logical framework of Figure 1 needs the identification of operational objectives and of the related plan actions. In order to define objectives and actions, we propose a methodological approach based on social media-related geographic information and apply the methodology to a case study concerning the masterplan of Cagliari, the regional capital city of Sardinia. In the next section, we introduce and discuss the concept of geographic information generated by social media's users, and the sources of this kind of information that we use to identify operational objectives and plan actions concerning the tourism-related sustainability objective of the MMP of Cagliari. In the following two sections, the four steps of the methodology are described and applied to the case study of the municipality of Cagliari. The four steps are: i. data collection and geocoding; ii. and iii. analyses of tourists' preferences at the regional and local levels; iv. implementation of spatial regressions in order to detect relations between tourists' locational preferences and location-related factors. In the discussion and concluding sections, we analyze the importance and effectiveness of geographic information generated by social media's users to improve the quality of MMPs' SEA processes, which are fundamentally based on the integration of this kind of information and the information collected from official sources, that is authoritative geographic information (AuGI).

\section{The Concept and Use of Geographic Information Generated by Social Media's Users}

The widespread diffusion of tourism social media platforms could offer new opportunities for decision-support in tourism planning. Tourists' satisfaction depends on factors related to the location and the quality of services that the local tourist enterprises make available. Moreover, analysis of tourists' satisfaction may offer valuable knowledge in tourism planning at the regional and local levels.

Here we propose an integrated approach to investigate, qualitatively and quantitatively, the relationships between tourists' satisfaction, geographic locations, and tourist enterprises in terms of support the tourism-related decision-making processes. The methodology implemented in the study includes data collection from the online tourism-related social networks Booking.com and TripAdvisor.com; that is, geographic information generated by social media's users, and integration of this information with authoritative territorial data, AuGI. The case study concerns the municipality of Cagliari and demonstrates the value of social media-related data integrated by authoritative information in tourism 
planning. We propose a critical discussion on the effectiveness of using the implemented integrated approach in order to address the definition of planning objectives in the context of SEA of MMPs.

Social networks provide users with a collection of various interactive opportunities [12], ranging from simple chat to multiple video conferences, and from exchange of plain email messages to participation in blogs and discussion forums. Tourists have ubiquitous access to a broad range of information services. They visit the Internet to share information and communication, to shop online, to express views, and to keep online blogs $[13,14]$. The development of a shared knowledge base is the driving force of online communities and, as a consequence, social, economic, and technological aspects are incorporated into the online communities $[15,16]$. Moreover, developments in social media imply that every piece of information can be commented or rated in some way. Through interactive platforms participants, tourists in the case of TriAdvisor.com and Booking.com, share, co-create, discuss, and modify the generated geographic information [17-19].

Geographic information generated by social media's users may be geocoded in different ways [20], using either the positions of the authors (if available), or the locations of the posts (recorded, for example, through a GPS sensor of a mobile device), or through toponyms parsing in the posts' texts.

Spatial data mining and geographic knowledge discovery are iterative processes that involve multiple steps, including data selection, cleaning, pre-processing, and transformation [20-22]. These methods are heuristic, inductive, and they include clustering, classification, rule mining, information visualization, and visual analysis [22]. They aim at integrating and further developing methods for the analysis of huge amounts of complex spatial data.

TripAdvisor.com and Booking.com are among the most popular platforms that generate geographic information. They play a significant role in the online tourism market. They can be considered as market-driven social media [23]. Moreover, they assist tourists in posting and sharing their travel-related comments. Tourists' opinions and personal experiences based on reconstruction of their trips generate important information available to scholars who study tourism-related social and market dynamics.

If information on the respondents' location is available, the information collected through tourism-related platforms is defined as volunteered geographic information (VGI). The term VGI has become popular to indicate the avalanche of information shared on the Web by users acting as sensors [24]. A frequently-discussed issue concerning user-generated content is the conceptual difference between explicit and implicit VGI [25-27]. This is related to the format of the content, the way of producing the content and the intention in generating the content [28]. Moreover, people involved in public participation-based geographic information systems provide planners, stakeholders, and the local communities with inputs and feedbacks that are very useful in public (non-Web) debates and Web-based discussions.

The opportunity of sharing information not only about the respondents' location but also about their biological, social, and cultural characteristics and feelings is further increasing due to interoperable, geographically-based Web programs [29]. VGI includes geographic information retrieved from communities through crowdsourcing geo-tagged data made available to the public in clouds by people who collected them for personal reasons $[29,30]$.

In this sense geographic information generated by social media's users can be defined as information collected through social networking Web or mobile applications with explicit or implicit geographic reference [19]. 
In the last two decades VGI has increasingly gained attractiveness to amateur users and professionals [26], resulting in a broader availability of urban data within VGI communities, and especially by the use of the OpenStreetMap application (OSM). OSM provides detailed information about urban regions, with particular reference to buildings' mapping. Moreover, user-generated content, such as localized tweets, Facebook places or Foursquare check-ins [27], is represented by Points of interest (POI). POIs could be considered as new forms of spatial projections of social relationships and perceived spatiality [31].

\section{A Geographic Information-Based Methodological Framework for Tourism Analysis}

The methodological approach builds on a preliminary heuristic analysis concerning social networks' contents related to the Sardinian region, in order to identify the most popular destinations, the relationships between the quality of tourist services and their locations, and the spatial distribution of tourists' preferences at the regional and local levels. We use geographic information data, in particular both AuGI and geographic information generated by social media's users. Combined AuGI and geographic information generated by social media's users are used to describe location.

The analysis framework is implemented, at the regional and local levels, by considering two dimensions (the quality of tourist services and their locations), using both AuGI and geographic information generated by social media's users. First of all, analysis at the regional scale is implemented to describe spatial patterns of tourists' preferences and to identify locations of interest. Afterwards, at the local level, that is, with reference to a particular cluster or spot of interest, further analyses were developed aiming at understanding the possible reasons which caused the detected patterns and singularities, that may help in explaining success- or failure-related factors concerning destinations' and services' features. We use a methodology based on spatial statistical and spatio-temporal textual analysis; that is, the analysis of texts which takes account of spatial and time-related constraints (indicated as "STTx" from now on) [19].

Operationally, the study is implemented through the following steps:

1. construction of a geocoded database whose records are retrieved from Booking.com and TripAdvisor.com;

2. implementation of a spatial analysis of opinions and attitudes of the local communities based on spatial statistics and STTx, and identification of clusters of TLSs which show concentration of preferred TLSs (hot spots as opposed to cold spots);

3. analysis of preferences expressed at the local level; data are integrated with AuGI from the Sardinian regional Spatial data infrastructure (SDI) and other official open data sources, in order to find explanatory hints on the tourists' preferences dynamics and to get insights on the relationships among the preferences, the local geography-related features and the quality of the tourism-related services at selected destinations;

4. estimate of a spatial regression to investigate spatial patterns within a particular tourist destination. By doing so, we describe the spatial distribution of the sign, magnitude, and significance of the influence of each explanatory (location-related) variable on the dependent variable, that is the level of satisfaction with the tourist destination. 
The first step consists of the construction of a database based on data extracted from TripAdvisor.com and Booking.com, which we collected for the period May 2012-May 2013. The focus of the two portals is to filter contents based on rankings, which are drawn from tourists' ratings. Rankings can be classified into several categories, such as value/price, rooms, location, cleanliness, and sleep quality. Since information concerning services' locations is available, it can be considered geographic information generated by social media's users [19].

The main issue is to manage this enormous amount of information. Thus, the study required the adoption of a mixed methodological approach, where quantitative information, concerning the scores of tourists' evaluation criteria, and qualitative information, including tourists' textual descriptive reviews, were collected in a database. TripAdvisor.com's ratings range from 1 ("terrible") to 5 ("excellent"), Booking.com from 1 to 10. Moreover, in both platforms, a text box allows tourists to express their opinions through text. Despite the lack of application programming interfaces (APIs) to access the services' information, the data extraction is performed by an ad hoc-implemented Javascript code that allows the Web content extraction. Then geocoding is performed on the extracted addresses. This makes it available information on the location of tourist facilities within the Sardinian region. Coordinates of the facilities were automatically detected in approximately $80 \%$ of the records, while approximately $20 \%$ of the geocoded locations were manually re-edited. A unified database of 992 records was finally defined. The records provide tourism lodging services' (TLSs) names, categories, locations, and related quantitative scores.

After the preliminary descriptive analysis of the preferences dataset, the second step of the methodology is the application of spatial analysis of tourism preferences to explore spatial patterns of positive tourists' judgments at the regional level. The application of spatial analytical techniques aims at exploring the spatial patterns of tourists' perception and their relationships with different variables. Visualizing this type of information on a map and interpreting derived results are difficult and, at times, illegible. This issue of representation has been overcome by using hot spot analysis (tool of ArcGIS 10.1 version; ESRI: Redlands, CA, United States). The hot spot analysis allows us to calculate the Getis-Ord $\mathrm{Gi}^{*}$ statistic for each feature in a dataset by looking at each feature in the same neighborhood [32]. The resultant $z$-scores and $p$-values give some clues of where features with either high or low values cluster spatially.

In the third step, the methodology adopted for this study shifted to the local scale for further analysis, aimed at finding explanatory answers for the phenomena under observation. The shift from the regional to the local scale was also conducted relying on spatial analysis and spatial statistics techniques on an integrated geographic information generated by social media's users/AuGI database. The aim is two-fold. On the one hand, the study is performed to discover why tourists prefer some destinations rather than others at the regional scale (qualitative analysis); on the other hand, we implement a quantitative assessment related to the location of tourists' preferences and to factors that contribute to high TPPI rates. We consider the tourist destination of Cagliari as an important reference point for our analysis since it shows a highly-successful tourist performance. The geographic information-based analysis assesses the success factors related to this destination; that is, the determinants (explanatory variables) of the high TPPI rates (dependent variable).

Moreover, the aim is to understand not only where people go but also what people think. This assessment is implemented by analyzing the review contents. The reasons implied by the tourists' preferences for 
certain destinations are detected through the STTx related to their reviews. The analysis is performed by means of the database of the tourists' comments, which collects data concerning the tourists' origin, language, and textual opinions. Textual analysis, which utilizes a tag cloud, makes it possible to detect information contained in the textual comments. Tag cloud is a visual representation of keywords (tags) contained in the textual strings of these comments.

In the final step, a spatial regression is used for both modeling the preferences phenomenon and testing the reliability of the hypothesis derived from textual analysis, in order to make appropriate decisions in terms of policy. The aim of the spatial regression is to discover what factors contribute to the TPPI rate. The model is applied to a sample of 150 TLSs spatially distributed over 100 of the 1359 Cagliari's census tracts. The dependent variable is the score of the TPPI, normalized as fraction of the comments that are favorable to a location belonging to a census tract.

In this context the spatial regression has been adopted to locate zones with homogeneous tourists' preferences within urban areas: zones of urban areas with homogeneous environmental, structural, and positional variables have been defined, excluding variables connected to specificity of property.

From the technical perspective, the spatial regression provides a local model of the tourists' preference, which represents the dependent variable, by fitting a regression equation to every feature in the dataset.

\section{Results}

The results are discussed according to the four points indicated at the end of the previous section.

\subsection{Data Collection and Geocoding}

The first step consists of the construction of a database based on data extracted from TripAdvisor.com and Booking.com, which we collected for the period May 2012-May 2013.

The analysis results reveal that the spatial distribution of the tourists' reviews on the TLSs is divided into five types of accommodation: agritourism (6\%), bed and breakfast (15.7\%), hotels (42\%), tourist houses $(29 \%)$, residences and resorts $(7.3 \%)$. Three provinces have emerged as important tourist destinations in the tourists' perceptions: Olbia-Tempio (27.8\%), Sassari (24\%), and Cagliari (20.6\%). The other Sardinia provinces are less represented in the TLSs related to the respondents (Nuoro 8.6\%, Oristano 7.3\%, Ogliastra 5\%, Carbonia-Iglesias 4\%, and Medio Campidano 3\%).

The analysis of the significance of tourists' appreciation related to the coastal and inner areas of Sardinia revealed that $92 \%$ of tourists' reviews of the sample concerns TLSs located in the coastal areas, while less than $8 \%$ are related to the inner areas. Nevertheless, Nuoro and Medio Campidano provinces together show appreciation of the local TLSs with about $13 \%$ of the total number of reviewed TLSs. This possibly indicates that tourists visit these areas to discover a less popular side of the island, which is characterized by its important natural, cultural heritage, and tradition-related resources. However, in terms of number of tourists, this kind of tourism can still not compete with preferences for the coastal areas. 


\subsection{Regional Preferences' Analysis at the Regional Level}

The second step consists of the spatial analysis of tourists' preferences to explore spatial patterns of positive judgments at the regional level.

The application of spatial analytical techniques aims at exploring the spatial patterns of tourists' perceptions and their relationships with other territorial variables. For each TLS, the database built from TripAdvisor.com and Booking.com includes a score record, which is the average of six attributes:

1. location (the TLS's geographic position);

2. services (presence of retail shops, bus stops, cafeterias, dining rooms and so on);

3. price/quality ratio;

4. staff (kindness);

5. room cleanliness (cleaning); and

6. the TLS's perceived comfort.

The first two attributes are related to the quality of the TLS's location, while the others concern the qualitative assessment of the TLS. Thus, through the available data we can investigate the spatial patterns of preferences across the whole region.

Data from Tripadvisor.com and Booking.com are normalized and ranked on the same scale. The six attributes are divided into two main categories which represent: i. location and ii. service quality. The analysis of the categories leads to discovering the level of satisfaction with the destination and its services, which may provide useful clues for choosing the most sustainable tourist options in case of other destinations.

Figure 2 shows the distribution of the tourists' positive preferences incidence (TPPI). The TPPI shows a high spatial concentration in North-eastern Sardinia. The Costa Smeralda district seems to be the only area where the global tourists' preferences fulfill overall tourists' expectations. The analysis at the municipal level shows that Alghero reveals the highest TPPI rate. The other two municipalities with a high TPPI are Cagliari and Olbia.

The map reported in Figure 2 not only detects locations already affected by the phenomenon, but also identifies areas suitable for future tourist developments. It is notable that most of the municipalities located along the coastal area attract tourists, while the inner areas represent a cold spot. Moreover, the presence of three major clusters representing the spatial distribution of TPPI within Sardinia is important as well. The first cluster is located in the Nurra district and includes the Sassari, Stintino, and Alghero municipalities. The presence of this cluster is probably due to the attractive power of the municipality of Alghero; that is, the only municipality which preserves the Catalan tradition. The second cluster is located in the Cagliari metropolitan area, which entails that Cagliari is strategic in terms of tourism attraction.

Finally, the last cluster covers a large part of the Gallura district, which represents a historical tourism landmark for the presence of the Costa Smeralda, which has been recognized as such since the 1960s due to Prince Aga Khan's massive investment. 


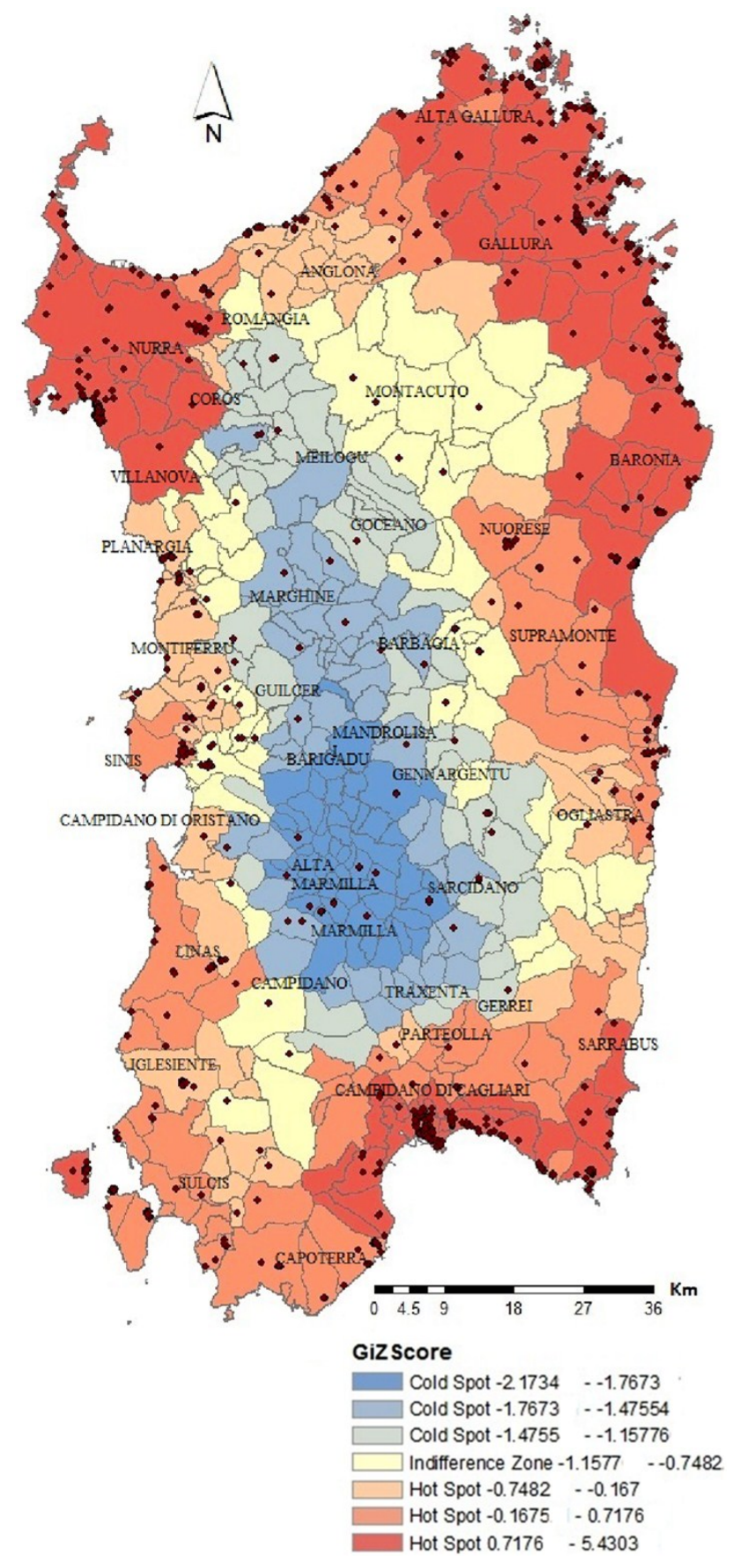

Figure 2. Clusters of tourists' positive preferences incidence (TPPI).

\subsection{Regional Preferences' Analysis at the Local Level}

After the analysis of tourism dynamics at the regional level, and the clusters' and the spots' identification in terms of successful destinations through the tourists' preference patterns, we considered the tourist destination of Cagliari for further analyses.

Cagliari, the capital city, is located in Southern Sardinia. It is nationally and internationally well connected thanks to the airport, the port, and the marina. Cagliari is the most important municipality in terms of trade and demographic size. Indeed, $50 \%$ of the Sardinian air traffic is related to the airport, with about 4 million passengers per year [33]. Records of our 2012-2013 database indicate that TLSs located in Cagliari are considered among the best-selling destinations by different tourists' typologies. 
The map in Figure 3 shows the spatial clusters of preferences. The location of each TLS immediately allows one to detect which sites the preferences of tourists who visited Cagliari are focused on; thus, it is possible to answer questions such as, "What areas, sites, or artifacts attract the tourists' attention?" Spatial clusters of preferences are detected by hot-spot analysis. Firstly, a threshold distance of $1700 \mathrm{~m}$ was identified and the spots by census tract summarized. The map in Figure 3 shows the spatial distribution of values of TPPI; the red areas, located in the inner areas of the municipality, show high concentration of the TPPI phenomenon (hot spot), while the blue areas represent locations where the phenomenon is less intense (cold spot). Not surprisingly, the inner areas of Cagliari attracts tourists while Pirri, a peripheral residential area of the Cagliari municipality, represents a cold spot.

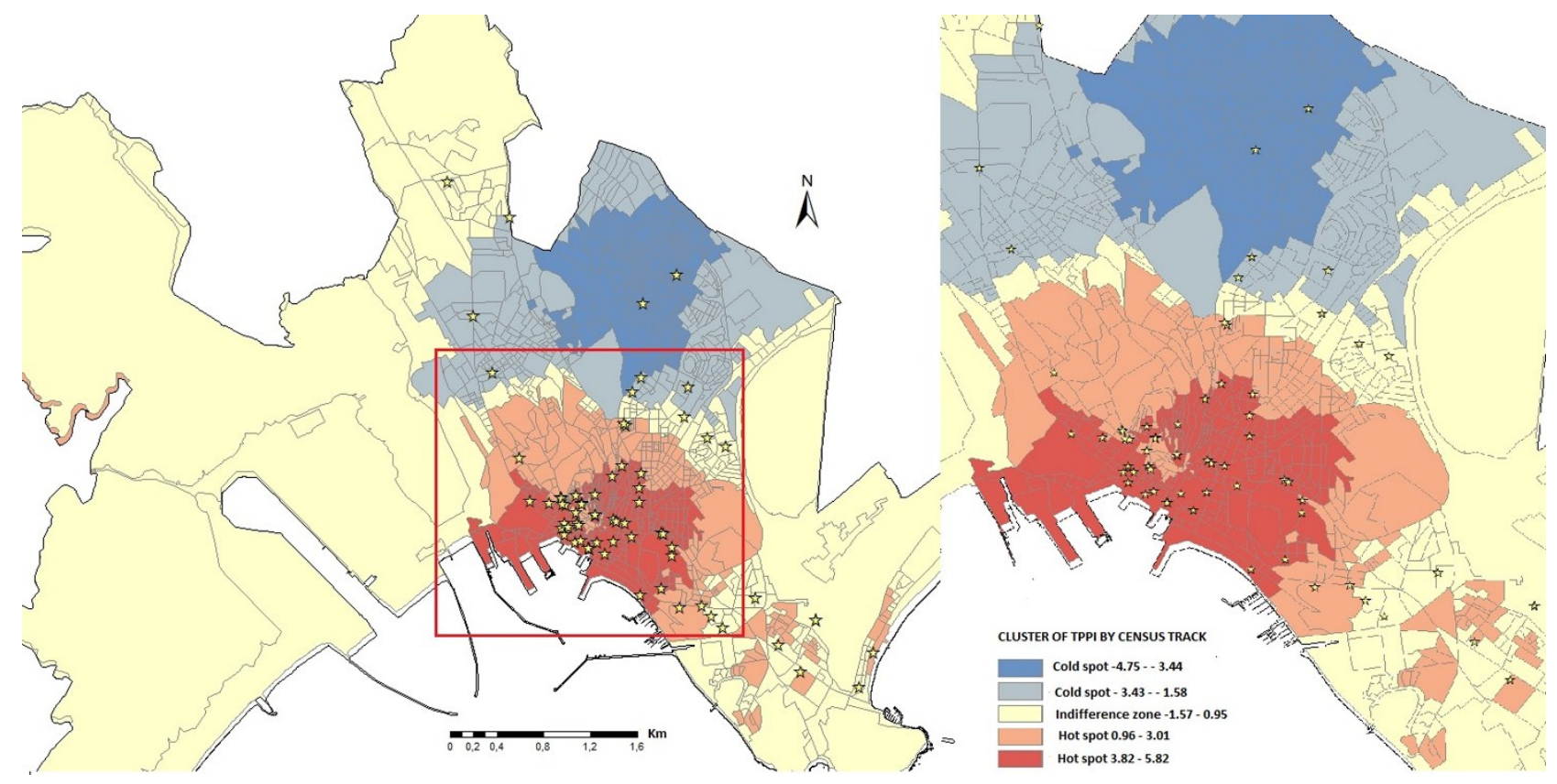

Figure 3. Significant patterns in Cagliari municipality.

The next step focuses on each review's content in order to understand not only "where" but also "what" tourists think about Cagliari. Hundreds of textual reviews have been investigated through STTx analysis. The opportunity of analyzing the tourists' preferences may help assess the spatial patterns related to attractive TLSs in order to detect useful hints to be used for the definition of planning policies in terms of tourism development at the local scale. Very interesting results have been obtained by applying STTx to local subsets of data obtained by selecting high TPPI values based on TLSs' locations. The tag cloud (Table 1) clearly shows that the majority of the words in the posts refer to spatial or physical aspects of the municipality, such as "center", "city", "location", and "church".

Table 1. Top 15 words related to Cagliari divided by category.

\begin{tabular}{cc}
\hline Category & Words (frequency) \\
\hline Geographic location & location (1010); town (476) \\
Service & staff (890); restaurant (643); room (459); hotel (469); pool (230); food (180) \\
Accessibility & minutes (250); harbor (237); proximity (164); walking (146) \\
\hline Natural and non & city center (426); beach (378); old city (132) \\
natural components & \\
\hline
\end{tabular}


The results include keywords related both to leisure sites, such as "restaurants", "shopping", and "dinner", and to services, such as "staff" and "room". Moreover, the outcomes indicate that a high level of satisfaction is related to accessibility: words as "minutes", "proximity", and "walking" could be related to the services' spatial location, natural resources or monuments. So, ease of movement from one site to another generates a positive tourist destination image. In addition, different sectors within the local community could benefit from the presence of tourists. Business sectors are more likely to hold favorable views on tourism because of the economic benefits it is perceived to bring. Nevertheless, local residents could have negative views, especially if their life quality is affected by noise, overcrowding, and overuse of local services and infrastructure. This is not the kind of information we usually find in land use-related planning documents, but it is powerful in supporting design and decision-making.

\subsection{Spatial Regression}

Finally, in our analysis we integrate geographic information generated by social media's users into AuGI concerning topography, transport infrastructure, cultural heritage sites, and socio-economic features. The spatial relationships and the explanatory factors behind observed spatial patterns were modeled using a spatial regression [34].

For each census tract, a measure of the set of independent variables was calculated. Preliminary results suggested excluding some explanatory variables from the model, because they did not comply with the Variance inflation factor (VIF) test. The VIF test provides a measure of the size of the multicollinearity generated by the inclusion of an explanatory variable in a ordinary-least-squares regression model. We assume that a variable should excluded from the set of the explanatory variables if the VIF is greater or equal to 10. [35]. The results of the statistical tests for measuring redundancy suggested that the following candidate's variables are included, normalized by the total area of the census tract:

1. number of historical buildings in the TLS' census tract (variable "N_hist_buildings" in Table 2);

2. number of restaurants and facilities in the TLS' census tract (variable "N_restaurants" in Table 2);

3. hectares of natural protected areas in the TLS' census tract (variable "H_natural_areas" in Table 2);

4. distance from the airport (variable "Distance_airport" in Table 2);

5. proximity to the historic center of the municipality (variable "Proxy_historic_center" in Table 2);

6. distance from the municipality's beach (variable "Distance_beach" in Table 2).

Table 2. Results of the spatial regression model: influence of each explanatory variable on dependent variable (tourist's preference).

\begin{tabular}{ccccc}
\hline Variable & Coefficient & Std. error & $\boldsymbol{z}$-value & $\boldsymbol{p}$-value \\
\hline TPPI_lag [19] & 0.0663 & 0.0307 & 2.1621 & 0.0306 \\
Constant & 0.0031 & 0.0102 & 0.3012 & 0.7633 \\
N_restaurants & -0.0390 & 0.0300 & -1.3013 & 0.1932 \\
Proxy_historic_center & 0.4748 & 0.0585 & 8.1146 & 0.0000 \\
N_hist_buildings & -0.0273 & 0.0313 & -0.8724 & 0.3830 \\
H_natural_areas & 0.0027 & 0.0096 & 0.2834 & 0.0777 \\
Distance_airport & 0.7661 & 0.0340 & 22.5511 & 0.0000 \\
Distance_beach & 0.5470 & 0.0383 & 14.2922 & 0.0000 \\
\hline
\end{tabular}


The assumption was that if the value of the normalized TPPI is similar to the values that it takes in the closest spatial units, the variable is characterized by spatial autocorrelation. A spatially-lagged explanatory variable is added to control for spatial autocorrelation of the dependent variable [36].

We introduce, among the covariates of the spatial regression, a spatially-lagged dependent variable (variable TPPI-lag in Table 2) which controls for the spatial autocorrelation of the dependent variable TPPI. We follow the methodology proposed by Anselin [37], and implemented by Zoppi and Lai [38].

The presence of spatial autocorrelation related to positive preference, whose value is the normalized TPPI, is detected through the Moran's test [37,39]. The result of the local Moran's index is quite significant at the second order of queen contiguity in respect of results obtained using a $2500 \mathrm{~m}$ spatial autocorrelation distance: adjusted R-squared is less than $40 \%$, the $p$-value of the coefficient of the dependent variable is very significant $\left(1.0 \times 10^{-8}\right)$ and the value of the Moran's index is 0.024 . The very low $p$-value indicates that local spatial autocorrelation of the dependent variable is highly significant.

The results concerning the goodness of fit of the spatial regression shown in Table 2 are significant: R-squared is as high as $86 \%$, which indicates that variables in the model explain about $86 \%$ of the variance of the positive tourists' preferences.

$\mathrm{R}$-squared is equal to the ratio of the difference between the total sum of squares of an ordinary-least-squares regression and the residual sum of squares, to the total sum of squares, that is the ratio of the explained sum of squares and the total sum of squares. In other words, $\mathrm{R}$-squared is a measure of the size of the variance of the dependent variable explained by the set of the explanatory variables. See, for example, the discussion proposed by Greene [40].The outcomes of the spatial regression model are quite significant for the description of the spatial distribution of tourists' preferences. The coefficients of the variables related to the proximity to the city center, to the distance from the airport, and to the proximity to the beach, which concern the TLSs' location, are almost always significant ( $p$-values less than 5\%) and show positive signs. The variables related to the historical buildings and to the restaurants are not very significant, for the $p$-values are greater than $10 \%$, while the hectares of natural protected areas show a coefficient significant at $8 \%$ and a positive sign.

Overall, these findings suggest that the spatial interest of the tourists is quantitatively influenced by the models' explanatory variables. The values of the coefficients, related to the TLSs' locations show positive effects of geographic position and facilities supply on the spatial patterns of tourists' preferences.

\section{Discussion}

The four-step methodological approach we described and applied to the municipality of Cagliari in the previous section operationalizes the logical framework reported in Figure 1 (see Figure 4), related to the SEA process concerning the MMP of Cagliari. The spatial regression results show that the sustainability objective defined, in Figure 1, as "Development of sustainable tourism based on attractive coastal environmental resources", would be effectively implemented through the following operational objectives (see Table 2, coefficients and $p$-values):

1. increased area of natural parks and reserves in the municipality of Cagliari, since the coefficient of variable "H_natural_areas" is positive and significant;

2. increased TLSs' proximity to the historic center of the municipality of Cagliari, since the coefficient of variable "Proxy_historic_center" is positive and significant; 
3. decreased TLSs' distance from the beach of the municipality of Cagliari, since the coefficient of variable "Distance_beach" is positive and significant.

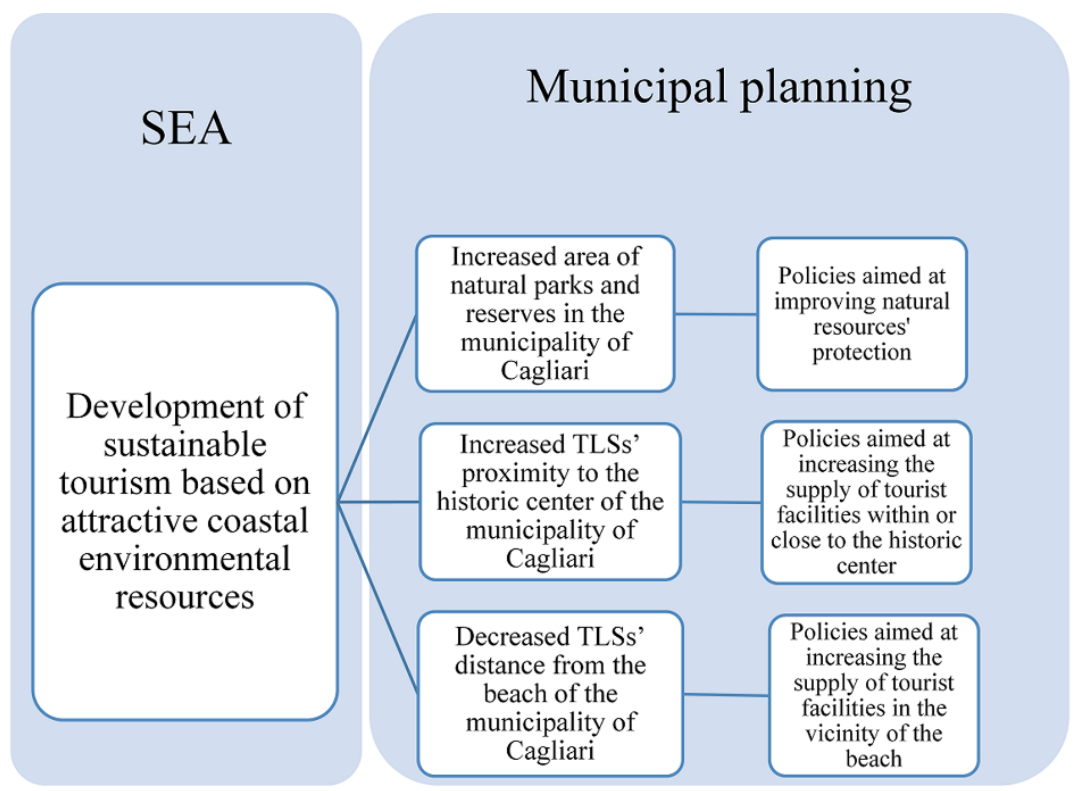

Figure 4. The logical framework implied by the implementation of the four-step methodology related to the SEA process concerning the MMP of Cagliari based on geographic information generated by social media's users.

Planning policies whose objective is to increase the tourists' satisfaction with TLSs located in the municipality of Cagliari can be straightforwardly identified, as well, e.g., as follows:

1. Operational objective 1 implies the implementation of policies aimed at improving protection of the municipality of Cagliari's natural resources in qualitative and quantitative terms;

2. Operational objective 2 implies policies aimed at improving the accessibility of the Cagliari's historic center, and at implementing urban renewal as breakfast facilities and so on) well, based on the restoration of residential buildings for tourist reception and hospitality (hotels, bed and within or close to the historic center; and

3. Operational objective 3 implies policies aimed at improving the accessibility of the Cagliari's beach and at increasing the supply of facilities for tourist reception and hospitality available in the vicinity of the beach.

The results of the methodological approach based on the integration of geographic information generated by social media's users and AuGI are very effective in terms of provision of information, which may possibly increase the spatial knowledge available for planning policy definition and implementation. In this perspective, geographic information generated by social media's users discloses opportunities for building analytical scenarios related to urban and regional planning and it offers useful suggestions for sustainable development based on tourism strategies. In an integrated planning support framework, the geographic information's analytics helps understanding tourists' observations, preferences, interests, feelings, and needs, and possibly it affects decision-making dynamics and urban and regional planning processes through tourists' oriented strategies. Moreover, the potential of geographic information from social media's users to generate useful knowledge for urban and regional planning 
fosters dialectics among tourists concerning locations and events by facilitating the integration of experiential and multifaceted information and expert knowledge.

\section{Concluding Remarks}

The study indicates that geographic information generated by social media's users is an effective support for analysis related to tourism planning. In this case, both tourists' preferences concerning destinations and tourism services were analyzed from a spatial perspective through the judgments collected by the social media platforms TripAdvisor.com and Booking.com. Spatial analysis and statistics techniques were used at the geographic scales, regional and local, to describe and visualize the spatial distribution of tourists' preferences and to detect patterns and hot spots. The findings provide insights on the Sardinian tourism dynamics which would not be available through other data sources used in spatial tourism planning.

The methodological approach implemented in this paper provides municipalities, planners, tourists, tourism entrepreneurship, and the local communities involved in the MMPs' SEA processes, with a detailed perspective of the issues at stake, based on progressive learning, which entails a continuous integration of geographic information generated by social media's users and AuGI which are continually evolving and improving in size and quality. These might also be involved in the process of defining and identifying relationships between tourists' preferences and factors related to the locational characteristics of the TLSs. The incrementally-built information, based on progressive inclusion and integration of geographic information generated by social media's users and AuGI, would increase the ease of accessibility to the involved stakeholders and the public.

Moreover, such a collective conceptualization of the MMPs' SEA-related information would strengthen the public awareness on the strong link between MMPs and the related SEAs, in terms of governance of the planning processes, whose ultimate goal is to improve life quality of local communities through spatial policies. This is identified as a key challenge by Healey. According to Healey, the first challenge (the so-called "analytical challenge") for planning theory "centres on how to conceptualize the relationships between government, wider governance and culture", while the second (the so-called "normative challenge") "centres on disentangling how governance activity informed by 'progressive' dreams about the future [...] can be distinguished from that which promotes narrowly-focused, elite-dominated and environmentally-damaging future options" [41].

Second, since the methodology here proposed is aimed at knowledge-building on a specific area of interest; that is, tourism in coastal areas, irrespective of potential applications, the approach we propose and apply to MMPs' SEA can be updated, refined and reused, and it can lay the foundation for the development of future applications in other consistent local planning contexts.

Moreover, considering tourists' preferences-related information could represent a significant issue for future research work in the field of tourism planning and management. Indeed, the analysis of the Sardinian case study emphasizes the importance of the role played by tourists in the context of inclusive processes. For instance, their behaviors can either strengthen or discourage the existing power relations.

Our results show that future studies related to the analysis of tourists' perceptions and expectations could be very effective in finding and proposing innovative policies related to tourism planning, design, and decision-making. 
Finally, a strong point of this paper is that the proposed and implemented methodological approach is suitable to be used by the countries whose plans and programs need to be assessed through SE; that is, all the countries that belong to the European Union, provided that small adjustments are put in place in order to apply our methodological approach in the member states. Furthermore, a semantic issue has to be taken into account as well, since the platforms we consider, TripAdvisor.com and Booking.com, are built in different languages, while the SEA process concerning the MMP of Cagliari is based on environmental and planning-related laws and regulations written in Italian.

\section{Author Contributions}

Roberta Floris and Corrado Zoppi have made substantial contributions to the essay's conception and design, background, discussion and concluding remarks. Corrado Zoppi has taken care of the introductory section. Roberta Floris has taken care of the second, third and fourth sections and subsections.

\section{Conflicts of Interest}

The authors declare no conflict of interest.

\section{References}

1. Thérivel, R.; Wilson, E.; Thompson, S.; Heany, D.; Pritchard, D. Strategic Environmental Assessment; Earthscan: London, UK, 1998.

2. Brown, A.; Thérivel, R. Principles to guide the development of strategic environmental assessment methodology. Impact Assess. Proj. Apprais. 2000, 18, 183-189.

3. Kørnøv, L.; Thissen, W. Rationality in decision- and policy-making: Implications for strategic environmental assessment. Impact Assess. Proj. Apprais. 2000, 18, 191-200.

4. Sadler, B.; Verheem, R. Strategic Environmental Assessment-Status, Challenges and Future Directions; Ministry of Housing, Spatial Planning and the Environment: The Hague, The Netherlands, 1996.

5. Partidário, M.R. Strategic environmental assessment: Key issues emerging from recent practice. Environ. Impact Assess. Rev. 1996, 1, 31-55.

6. Partidário, M.R. Strategic environmental assessment-Principles and potential. In Handbook on Environmental Impact Assessment; Petts, J., Ed.; Blackwell: London, UK, 1999; pp. 60-73.

7. Devuyst, D. Linking impact assessment with sustainable development and the introduction of strategic environmental assessment. In How Green is the City? Sustainability Assessment and the Management of Urban Environments; Devuyst, D., Hens, L., de Lannoy, W., Eds.; Columbia University Press: New York, NY, USA, 2001; pp. 129-155.

8. Nitz, T.; Brown, A.L. SEA must learn how policy making works. J. Environ. Assess. Policy Manag. 2001, 3, 329-342.

9. Castiglioni, B.; de Marchi, M. (Eds.) Paesaggio, Sostenibilità, Valutazione [Landscape, Sustainability, Assessment]. Quaderni del Dipartimento di Geografia dell’Università di Padova n. 24 [Workbooks of the Department of Geography of the University of Padua n. 24], 2007. Available online: http://wug.cab.unipd.it:8080/DigLib/DataBase/repository/1181806398/Quaderno_di_Geografia_2 4.pdf (accessed on 22 July 2015). 
10. Sheate, W.; Dagg, S.; Richardson, J.; Aschemann, R.; Palerm, J.; Steen, U. SEA and Integration of the Environment into Strategic Decision-Making; ICON: London, UK, 2001; Volumes 1, 2, 3.

11. Regione Autonoma della Sardegna [Sardinia Autonomous Region]. Linee Guida per la Valutazione Ambientale Strategica dei Piani Urbanistici Comunali [Guidelines for Strategic Environmental Assessment of City masterplans]. Allegato alla Delibera della Giunta Regionale della Regione Autonoma della Sardegna [Annex to the Deliberation of the Regional Government of Sardinia Autonomous Region] n. 44/51, 14 December 2010. Available online: http://www.sardegnaambiente.it/ index.php? $\mathrm{xsl}=1399 \& \mathrm{~s}=18 \& \mathrm{v}=9 \& \mathrm{c}=8280 \& \mathrm{es}=4272 \& \mathrm{na}=1 \& \mathrm{n}=10($ accessed on 22 July 2015$)$.

12. Miguéns, J.; Baggio, R.; Costa, C. Social Media and Tourism Destinations: Tripadvisor Case Study. Paper presented at IASK ATR 2008 (Advances in Tourism Research), Aveiro, Portugal, 26-28 May 2008, pp. 26-28. Available online: http://www.iby.it/turismo/papers/baggio-aveiro2.pdf (accessed on 22 July 2015).

13. Buhalis, D. Strategic use of information technologies in the tourism industry. Tour. Manag. 1998, 19, 409-421.

14. Chung, J.Y.; Buhalis, D. Web 2.0: A study of online travel community. In Information and Communication Technologies in Tourism; O’Connor, P., Höpken, W., Gretzel, U., Eds.; SpringerWienNewYork: Vienna, Austria, 2008; pp. 70-81.

15. Fernback, J. There is a there there. Notes toward a definition of cybercommunity. In Doing Internet Research. Critical Issues and Methods for Examining the Net; Jones, S., Ed.; Sage: Thousand Oaks, CA, USA, 1998; pp. 203-220.

16. Gleave, E. A conceptual and operational definition of 'social role' in online community. In Proceedings of the 42nd Hawaii International Conference on System Sciences, 2009, Big Island, HI, USA, 5-8 January 2009; pp. 1-11.

17. Kietzmann, J.H.; Hermkens, K.; McCarthy, I.P.; Silvestre, B.S. Social media? Get serious! Understanding the functional building blocks of social media. Bus. Horiz. 2011, 54, 241-251.

18. Floris, R.; Campagna, M. Social media geographic information in tourism planning. TeMA J. Land Use Mobil. Environ. 2014, 8, 418-430.

19. Campagna, M. The geographic turn in social media: Opportunities for spatial planning and geodesign. In Proceedings of the 14th International Conference on Computational Science and its Applications (ICCSA 2014), Guimaraes, Portugal, 30 June-3 July 2014; pp. 598-610.

20. Mennis, J.; Diansheng, G. Spatial data mining and geographic knowledge discover. An introduction. Comput. Environ. Urban Syst. 2009, 33, 403-408.

21. Andrienko, G.L.; Andrienko, N.V. Interactive maps for visual data exploration. Int. J. Geogr. Inf. Sci. 1999, 13, 355-374.

22. Miller, H.J. The Data avalanche is here. Shouldn't we be digging? J. Reg. Sci. 2010, 50, 181-201.

23. Briassoulis, H. Sustainable tourism and the question of the commons. Ann. Tour. Res. 2002, 29, 1065-1085.

24. Goodchild, M. Citizen as voluntary sensors: Spatial data infrastructure in the world of Web 2.0. Int. J. Spat. Data Infrastruct. 2007, 2, 24-32.

25. Cook, S. Why contributors contribute. 2008. Available online: http://usercontribution.intuit.com/ w/page/18238320/Why\%20contributors\%20contribute?rev=1223398673 (accessed on 22 July 2015). 
26. Coleman, D.J.; Georgiadou, Y.; Labonte, J. Volunteered geographic information: The nature and motivation of produsers. Int. J. Spat. Data Infrastruct. Res. 2009, 4, 332-358.

27. Craglia, M.; Ostermann, F.; Spinsanti, L. Digital Earth from vision to practice: Making sense of citizen-generated content. Int. J. Digit. Earth 2012, 5, 398-416.

28. Sieber, R. Public participation geographic information systems: A literature review and framework. Annals of the American Association of Geography 2006, 96, 491-507.

29. Sui, D.; Goodchild, M. The convergence of GIS and social media: Challenges for GIScience. Int. J. Geogr. Inf. Sci. 2011, 25, 1737-1748.

30. Campagna, M.; Kudinov, A.; Girsheva, A.; Ivanov, K.; Kopnov, M.; Falqui, R. Place I care! Crowdsourcing planning information. In Proceedings of the AESOP-ACSP Joint Congress. Dublin, 2013, Dublin, Ireland, 15-19 July 2013.

31. Roche, S.; Rajabifard, A. Sensing places' life to make city smarter. In UrbComp '12 Proceedings of the ACM SIGKDD International Workshop on Urban Computing; ACM: New York, NY, USA, 2012; pp. 41-46.

32. Getis, A.; Ord, J.K. The analysis of spatial association by use of distance statistics. Geogr. Anal. 1992, 24, 189-206.

33. Benedetti, G.; Gobbato, L.; Perboli, G.; Perfetti, F. The Cagliari Airport impact on Sardinia tourism: A Logit-based analysis. Procedia Soc. Behav. Sci. 2012, 54, 1010-1018.

34. Fotheringham, A.S.; Brunsdon, C.; Charlton, M.E. Geographically Weighted Regression: The Analysis of Spatially Varying Relationships; John Wiley and Sons: West Sussex, UK, 2002.

35. Mennis, J. Mapping the results of geographically weighted regression. Cartogr. J. 2006, 43, 171-179.

36. Anselin, L. Local indicators of spatial association-LISA. Geogr. Anal. 1995, 27, 93-115.

37. Anselin, L. Spatial Econometrics: Methods and Models; Kluwer Academic Publishers: Dordrecht, The Netherlands, 1988.

38. Zoppi, C.; Lai, S. Land-taking processes: An interpretive study concerning an Italian region. Land Use Policy 2014, 36, 369-380.

39. Moran, P.A.P. Notes on continuous stochastic phenomena. Biometrika 1950, 14, 17-33.

40. Greene, W.H. Econometric Analysis; Macmillan: New York, NY, USA; pp. 150-155.

41. Healey, P. Introduction to part one. In The Ashgate Research Companion to Planning Theory. Conceptual Challenges for Spatial Planning; Hillier, J., Healey, P., Eds.; Ashgate Publishing Limited: Farnham, UK, 2010; pp. 37-55.

(C) 2015 by the authors; licensee MDPI, Basel, Switzerland. This article is an open access article distributed under the terms and conditions of the Creative Commons Attribution license (http://creativecommons.org/licenses/by/4.0/). 